\title{
Regional differences between superficial and deep lumbar multifidus in patients with chronic lumbar spine pathology
}

Jennifer Padwal ${ }^{1 \dagger}$, David B. Berry ${ }^{2 \dagger}$, James C. Hubbard ${ }^{3}$, Vinko Zlomislic ${ }^{3}$, R. Todd Allen ${ }^{3}$, Steven R. Garfin ${ }^{3}$, Samuel R. Ward ${ }^{3,4,5}$ and Bahar Shahidi ${ }^{*}$

\begin{abstract}
Background: Due to its unique arrangement, the deep and superficial fibers of the multifidus may have differential roles for maintaining spine stabilization and lumbar posture; the superficial multifidus is responsible for lumbar extension and the deep multifidus for intersegmental stability. In patients with chronic lumbar spine pathology, muscle activation patterns have been shown to be attenuated or delayed in the deep, but not superficial, multifidus. This has been interpreted as pain differentially influencing the deep region. However, it is unclear if degenerative changes affecting the composition and function of the multifidus differs between the superficial and deep regions, an alternative explanation for these electrophysiological changes. Therefore, the goal of this study was to investigate macrostructural and microstructural differences between the superficial and deep regions of the multifidus muscle in patients with lumbar spine pathology.
\end{abstract}

Methods: In 16 patients undergoing lumbar spinal surgery for degenerative conditions, multifidus biopsies were acquired at two distinct locations: 1) the most superficial portion of muscle adjacent to the spinous process and 2) approximately 1 $\mathrm{cm}$ lateral to the spinous process and deeper at the spinolaminar border of the affected vertebral level. Structural features related to muscle function were histologically compared between these superficial and deep regions, including tissue composition, fat fraction, fiber cross sectional area, fiber type, regeneration, degeneration, vascularity and inflammation.

Results: No significant differences in fat signal fraction, muscle area, fiber cross sectional area, muscle regeneration, muscle degeneration, or vascularization were found between the superficial and deep regions of the multifidus. Total collagen content between the two regions was the same. However, the superficial region of the multifidus was found to have less loose and more dense collagen than the deep region.

Conclusions: The results of our study did not support that the deep region of the multifidus is more degenerated in patients with lumbar spine pathology, as gross degenerative changes in muscle microstructure and macrostructure were the same in the superficial and deep regions of the multifidus. In these patients, the multifidus is not protected in order to maintain mobility and structural stability of the spine.

Keywords: Low back pain, Skeletal muscle, Multifidus, Degeneration, Atrophy, Fatty infiltration, Lumbar spine, Lumbar spine pathology, Inflammation, Surgery

\footnotetext{
* Correspondence: bshahidi@health.ucsd.edu

†Jennifer Padwal and David B. Berry contributed equally to this work.

${ }^{3}$ Departments of Orthopaedic Surgery, University of California, 9500 Gilman

Drive (MC0863), La Jolla, San Diego, CA 92093, USA

Full list of author information is available at the end of the article
}

(C) The Author(s). 2020 Open Access This article is licensed under a Creative Commons Attribution 4.0 International License, which permits use, sharing, adaptation, distribution and reproduction in any medium or format, as long as you give appropriate credit to the original author(s) and the source, provide a link to the Creative Commons licence, and indicate if changes were made. The images or other third party material in this article are included in the article's Creative Commons licence, unless indicated otherwise in a credit line to the material. If material is not included in the article's Creative Commons licence and your intended use is not permitted by statutory regulation or exceeds the permitted use, you will need to obtain permission directly from the copyright holder. To view a copy of this licence, visit http://creativecommons.org/licenses/by/4.0/. The Creative Commons Public Domain Dedication waiver (http://creativecommons.org/publicdomain/zero/1.0/) applies to the data made available in this article, unless otherwise stated in a credit line to the data. 


\section{Background}

In patients with low back pain (LBP) arising from degenerative lumbar conditions, the lumbar multifidus muscle is often observed to have increased fatty infiltration and atrophy compared to similarly aged controls [1], resulting in reduced long-term function and poor prognosis [2-5]. As the multifidus muscle is considered to be a key stabilizer of the lumbar spine [6] - due to its ability to produce high forces over a narrow range of lengths degenerative changes to the composition and thereby function of this muscle are thought to have profound effects on degenerative lumbar spine disease. This has driven interest in understanding changes in multifidus quality in patients with lumbar spine pathology, in order to determine appropriate treatment strategies to mitigate pathological changes to the multifidus and improve stability of the spinal column [7].

Several studies have investigated microscopic (i.e. cell level) and macroscopic (i.e. whole muscle level) changes in multifidus structure in patients with chronic LBP due to lumbar spine pathology (LSP). Microscopically, type II muscle fiber atrophy, an increased proportion of glycolytic compared to oxidative muscle fibers, decreased vascularity, elevated inflammatory cell count, increased numbers of centrally nucleated fibers, and muscle fiber degeneration has been observed in muscle biopsies obtained from individuals with chronic lumbar spine pathology [8-11]. Macroscopically, pathological changes in the multifidus of patients with LBP such as increases in intramuscular fat infiltration $[1,10,12,13]$ and decreases in cross-sectional area ipsilateral to the side of reported pain [7] have been observed using magnetic resonance imaging (MRI) of the lumbar spine. Qualitatively, intramuscular fat infiltration appears to accumulate in the medial and deep regions of the multifidus in MRI, however regional infiltration of fat in the paraspinal muscles has not been quantified. Given the known effects of chronic lumbar spine pathology on multifidus muscle health, many physical therapy regimens have attempted to reverse structural changes (i.e. hypertrophy, fatty infiltration reversal) in order to restore spinal stability and reduce pain [14]. However, improvements in muscle structure are rarely observed in response to most rehabilitation programs [15-18].

The multifidus muscle is uniquely arranged with superficial fibers spanning two to five levels and located further from the vertebral center of rotation than deep fibers, which cross two levels near the vertebral center of rotation [19-22]. As such, it has been proposed that the larger moment arm of the superficial fibers contributes to extension of the lumbar spine and control of lumbar lordosis [23], whereas the shorter moment arm of the deep fibers contributes to intersegmental compression and stabilization [24]. In addition to mechanically distinct features, differences in muscle activation have been observed using electromyography (EMG) of the superficial and deep multifidus in response to rapid arm movement; the onset of reactive muscle activation in response to arm movement is dependent upon arm swinging direction in the superficial multifidus, but independent of direction in the deep multifidus [25]. This could suggest a more tonic activation pattern for the deep multifidus than the superficial multifidus. In combination, these architectural differences along with observed differences in muscle activation patterns have led to the hypothesis that the superficial and deep multifidus are functionally distinct [22, 26-28]. Similarly, in the presence of LBP, the muscle activation patterns have been shown to be attenuated or delayed in the deep, but not superficial multifidus. This suggests that pain differentially influences the deep region of muscle $[29,30]$. As a result, many physical rehabilitation paradigms attempt to specifically target strengthening the deep multifidus in order to restore normal stability and function [31].

While there are different anatomic, histologic, biomechanical, and neuromuscular behavior patterns of the deep and superficial regions of the multifidus, it is unknown if these regions are differentially affected by LSP. Therefore, the purpose of this study was to investigate macrostructural and microstructural differences between the superficial and deep regions of the multifidus muscle in patients with LSP. Specifically, structural features related to muscle function were compared including fat fraction, fiber cross sectional area, fiber type, regeneration, degeneration, vascularity and inflammation. We hypothesized that in a pathologic multifidus muscle, the deep region of the multifidus will exhibit macrostructural and microstructural degeneration compared to the superficial region of the multifidus.

\section{Methods \\ Participants}

This was a prospective observational cohort study of 16 patients who underwent lumbar spinal surgery between 2015 and 2016. Patients were included if they were undergoing a primary posterior-approach procedure to address LSP (lumbar stenosis, spondylolisthesis, or disc herniation), and did not have any diagnosed myopathy or systemic neurological condition. All patients provided informed consent for participation in accordance with the declaration of Helsinki and the study protocol was approved by the University of California, San Diego Institutional Review Board.

\section{Biopsy samples}

Biopsies (approximately $100 \mathrm{mg}$ ) were harvested from the multifidus muscle during surgical approach using a special clamp to keep the tissue at in vivo length [32] at two distinct locations: 1 ) the most superficial portion of 
muscle adjacent to the spinous process (designated the "superficial" sample) and 2) approximately $1 \mathrm{~cm}$ lateral to the spinous process at the spinolaminar border of the affected vertebral level (designated as the "deep" sample) (Fig. 1). Each surgeon was trained by the same research staff on the appropriate location of the biopsy and researchers verified the biopsy location for each procedure. Biopsies were excised upon initial approach in order to maximize anatomical consistency and avoid the influence of retraction. Biopsies were immediately pinned at in vivo length and flash frozen in liquid nitrogen cooled isopentane [32]. Frozen samples were transported back to the laboratory on dry ice and were stored at $-80^{\circ} \mathrm{C}$ until processing. Samples were embedded in optimal cutting temperature compound, and cut into $10 \mu \mathrm{m}$ sections using a cryostat (Leica CM3050S, Buffalo Grove, IL).

Tissue morphology and composition were visualized using Hematoxylin and Eosin (H\&E) and Gomori Trichrome stains (Fig. 2) [33]. Relative fractions of muscle, fat, and collagen were quantified from Trichrome stained biopsies using ImageJ software [34]. Manual intensity thresholding was used for tissue type segmentation between red (muscle), green (loose collagen), and blue (dense collagen) channels of whole section slides. Adipose tissue was identified morphologically and manually traced. To quantify muscle fiber area and centrally nucleated fibers, samples were stained with Laminin-111 or Laminin-211 to identify muscle basal laminar borders (LAMA1 (Sigma L9393) or LAMA2 (Vector VP-M648)), Type I (Hybridoma Bank BA-D5) and IIa (Hybridoma Bank SC-71) Myosin Heavy Chain antibodies to identify fiber type, counterstained with 4' 6-diamidino-2-phenylindole (DAPI) to identify cell nuclei, and then coverslipped with Vectashield mounting medium (Vector H-5000). Six randomly generated frames from biopsy cross-sections were used to quantify fiber area and centrally nucleated fibers (a measure of regeneration/degeneration) by counting cells with DAPI signal within the muscle fiber area. Vascularity was measured by counting the number of Von Willebrand Factor (Sigma F3520) positive vessels $/ \mathrm{mm}^{2}$, [35]. Muscle regenerative capacity was measured by calculating the number of $\mathrm{Pax}^{+}$satellite cells per muscle fiber from 10 randomly generated 20x fields. Muscle degeneration was quantified by manually evaluating the proportion of 1 $\mathrm{mm}^{2}$ grids across an entire section of muscle that contained degenerative muscle fibers including: moth eaten fibers, cell infiltration, core fibers, and myophagocytosis as previously described [36].

\section{MRI measurements}

Preoperative MRIs from 15 biopsied patients were obtained from our hospital database (1 patient had no preoperative MRI available). Regions of interest (ROI) measuring $1 \mathrm{~cm}^{2}$

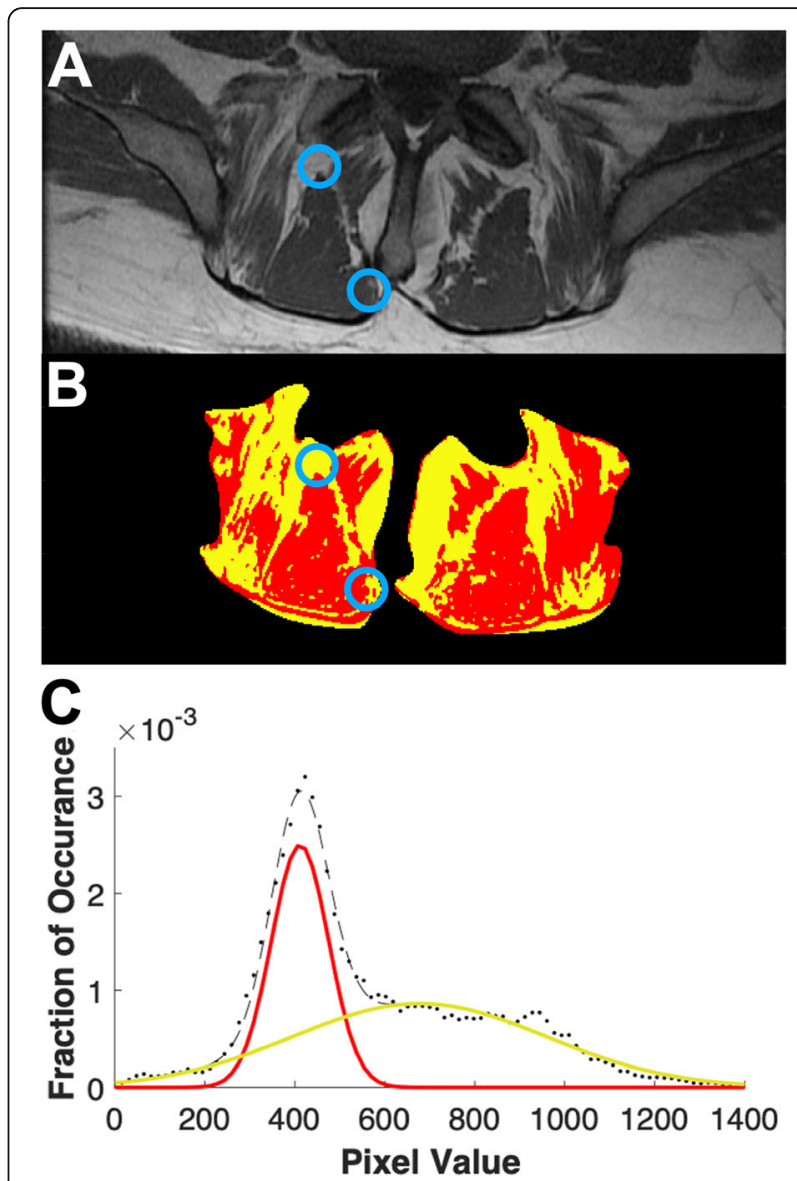

Fig. 1 a Example MRI used to calculate fat signal fraction. Blue circles indicate approximate location where biopsies were taken from and fat signal fraction measurements were made. $\mathbf{b}$ Fat signal fraction map of MRI in (a). Red indicates voxels classified as muscle, yellow indicates voxels classified as fat. c Histogram of pixel intensities in (a) across a spectrum of fat (yellow) and muscle (red). Thresholds were defined on a patient-by-patient basis as the intersection between the Gaussian distribution of fat and water

were isolated from T1-weighted axial magnetic resonances images taken at a single slice at the vertebral level and side that the biopsies were taken (Fig. 1a, b). A custom written Matlab (Mathworks, Natick MA) code was used to measure the fat signal fraction (FSF) within the ROI [1,37]. Pixels within the ROI were identified as either fat or muscle based on pixel intensity, where a two term gaussian model was fit to the histogram of pixel intensities and the threshold was set at the intersection of the gaussian distributions. Pixel values below the threshold were classified as muscle and pixels above were classified as fat (Fig. 1c) [1, 37].

\section{Statistical analysis}

Paired t-tests were used to evaluate the difference in histologic- (tissue composition, fiber area (by fiber type), centralized nuclei, vascularity, degeneration) and MRIbased (fat signal fraction) measures of muscle health 


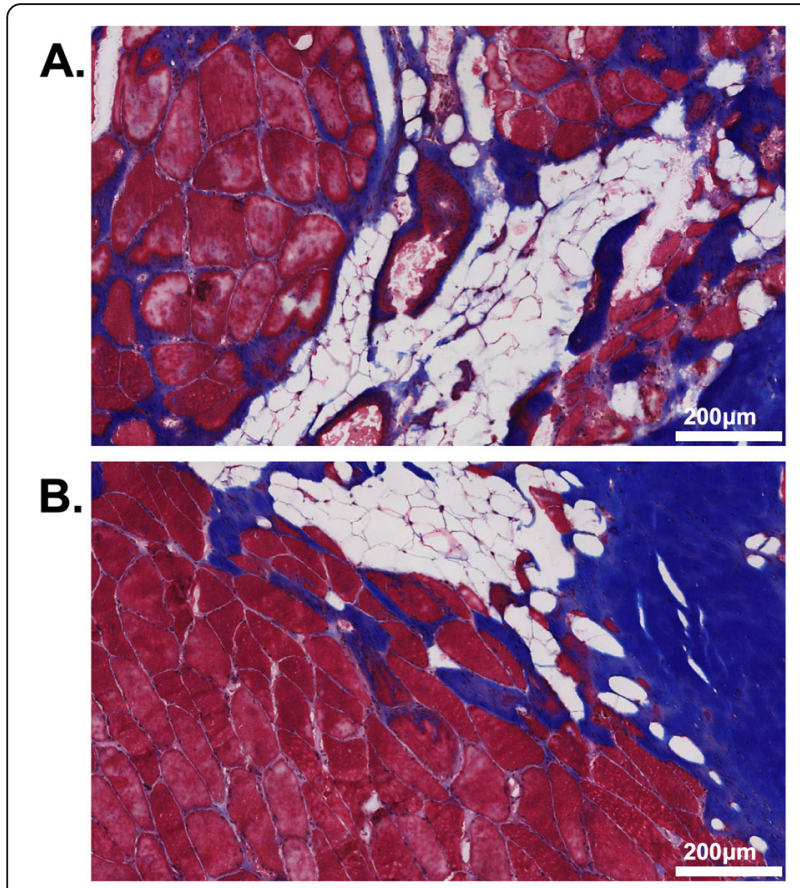

Fig. 2 Gomori trichrome stained biopsy section demonstrating regions of muscle, collagen, and fat from superficial (a) and deep (b) multifidus biopsies

between the superficial and deep regions of the multifidus. The threshold for statistical significance $(\alpha)$ was set to 0.05 for all analyses. Effect size (Cohens d [38]) was calculated for all statistical tests. Data are reported as mean \pm standard deviation. Statistical analyses were performed using Prism 8 (GraphPad, La Jolla, CA).

\section{Results}

The average age of participants was 61.9 years \pm 17.3 years with 6 female patients. The average duration of symptoms in these patients was 3.8 years \pm 6.1 years. Surgeries were performed for a diagnosis of lumbar stenosis in 12 patients, spondylolisthesis in 2 patients, and disc herniation in 2 patients. There was an equal distribution between biopsies taken on the L vs $\mathrm{R}$ side (Table 1). Effect size (d) for all comparisons is reported in Table 2.

\section{Histologic differences between superficial and deep biopsies of the multifidus muscle}

Overall, biopsy samples were composed of $11.1 \% \pm 9.1 \%$ fat, $49.2 \% \pm 15.7 \%$ muscle, and $26.2 \% \pm 12.4 \%$ collagen . No significant difference was found for the area fraction of fat $(p=0.67, \mathrm{~d}=0.10)$, muscle $(p=0.16, \mathrm{~d}=0.34)$, or total collagen $(p=0.59, \mathrm{~d}=0.14)$ between superficial and deep samples (Fig. 3a, b). However, superficial biopsies were found to have a greater average proportion of dense collagen $(17.18 \%$ vs $10.09 \%, p=0.034, \mathrm{~d}=0.42)$ and smaller average proportion of loose collagen $(9.86 \%$
Table 1 Demographics of patients included in this study

\begin{tabular}{ll}
\hline Age (years) & $\mathbf{6 1 . 9 \pm 1 7 . 3}$ \\
\hline Gender (M:F) & $10: 6$ \\
Duration of Symptoms (years) & $3.8 \pm 6.1$ \\
Biopsy Side (L:R) & $8: 8$ \\
Biopsy Level & \\
L3 & 5 \\
L3-L4 & 4 \\
L4 & 1 \\
L4-L5 & 5 \\
L5 & 0 \\
L5-S1 & 1 \\
NPRS (points) & $5.7 \pm 2.5$ \\
ODI (\%) & $47.6 \pm 17.9$ \\
\hline
\end{tabular}

NPRS numeric pain rating scale, ODI Oswestry disability index

vs $15.23 \%, p<0.01, \mathrm{~d}=0.64)$ compared to deep biopsies (Fig. 3c). No significant difference in either type I ( $p=$ $0.77, \mathrm{~d}=0.05)$ or type II $(p=0.40, \mathrm{~d}=0.01)$ fiber area was found between superficial and deep samples (Fig. 4a, b). Additionally, there was no significant difference in the distribution of type I $(p=0.97, \mathrm{~d}=0.04)$, type IIa $(p=0.95, \mathrm{~d}=0.13)$, and type IIx $(p=0.90, \mathrm{~d}=0.09)$ fibers between superficial and deep samples (Fig. 4c).

Histologic markers of muscle regeneration and degeneration were increased, and vascularity was decreased compared to literature based reports from normal muscle (Fig. 5) [39-41]. However, no significant difference was found between superficial and deep multifidus biopsies for fraction of fibers with centralized nuclei $(p=0.85, \mathrm{~d}=$

Table 2 Cohen's effect size (d) analysis for all statistical comparisons

\begin{tabular}{ll}
\hline Measurement & Effect size \\
\hline Area fraction fat & 0.11 \\
Area fraction muscle & 0.34 \\
Area fraction collagen & 0.14 \\
Dense collagen & 0.64 \\
Loose collagen & 0.85 \\
Type I fiber area & 0.01 \\
Type II fiber area & 0.33 \\
Distribution type I & 0.04 \\
Distribution type lla & 0.13 \\
Distribution type llx & 0.09 \\
\% centralized nuclei & 0.21 \\
\% Pax $7^{+}$ & 0.29 \\
\% von Willebrand factor & \\
Degeneration & 0.69 \\
MRI fat signal fraction & 0.20 \\
\hline
\end{tabular}



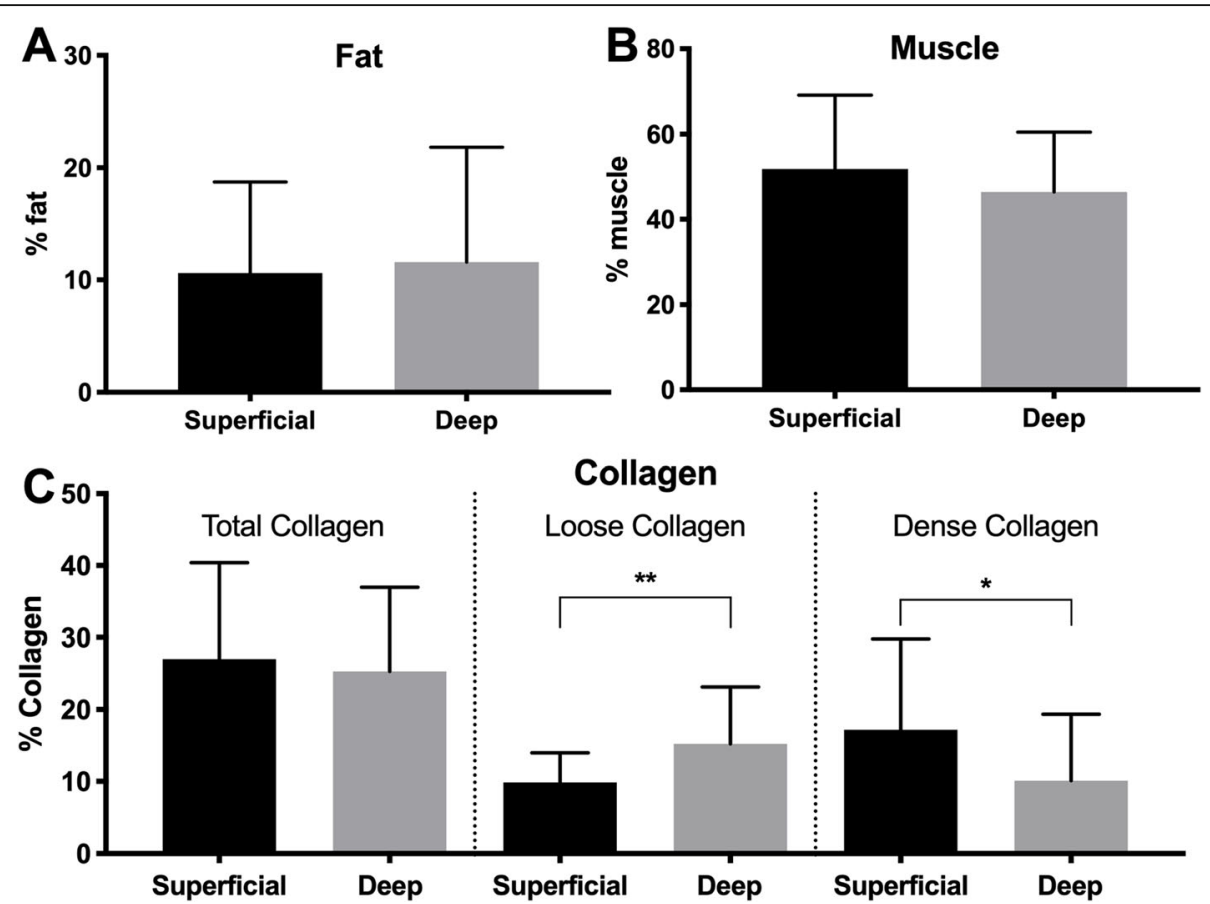

Fig. 3 Histologic evaluation of tissue composition. Area fraction of fat (a), muscle (b), and collagen (c) of superficial (black) and deep (gray) biopsy samples. ${ }^{*}-p<0.05 ;{ }^{*}-p<0.01$

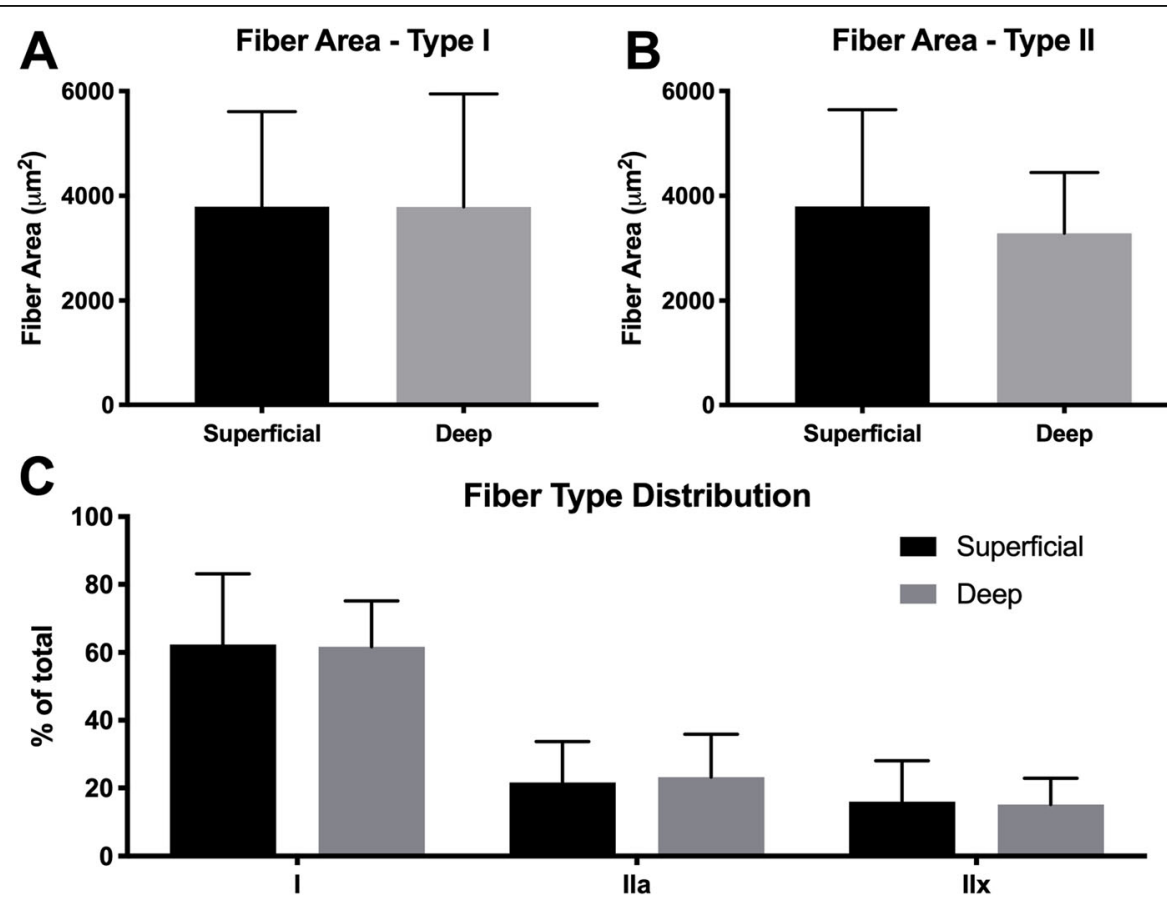

Fig. 4 Fiber area of type I (a) and type II (b) muscle fibers for superficial (black) and deep (gray) biopsy samples. c Distribution of fiber types between superficial (black) and deep (gray) biopsy samples 

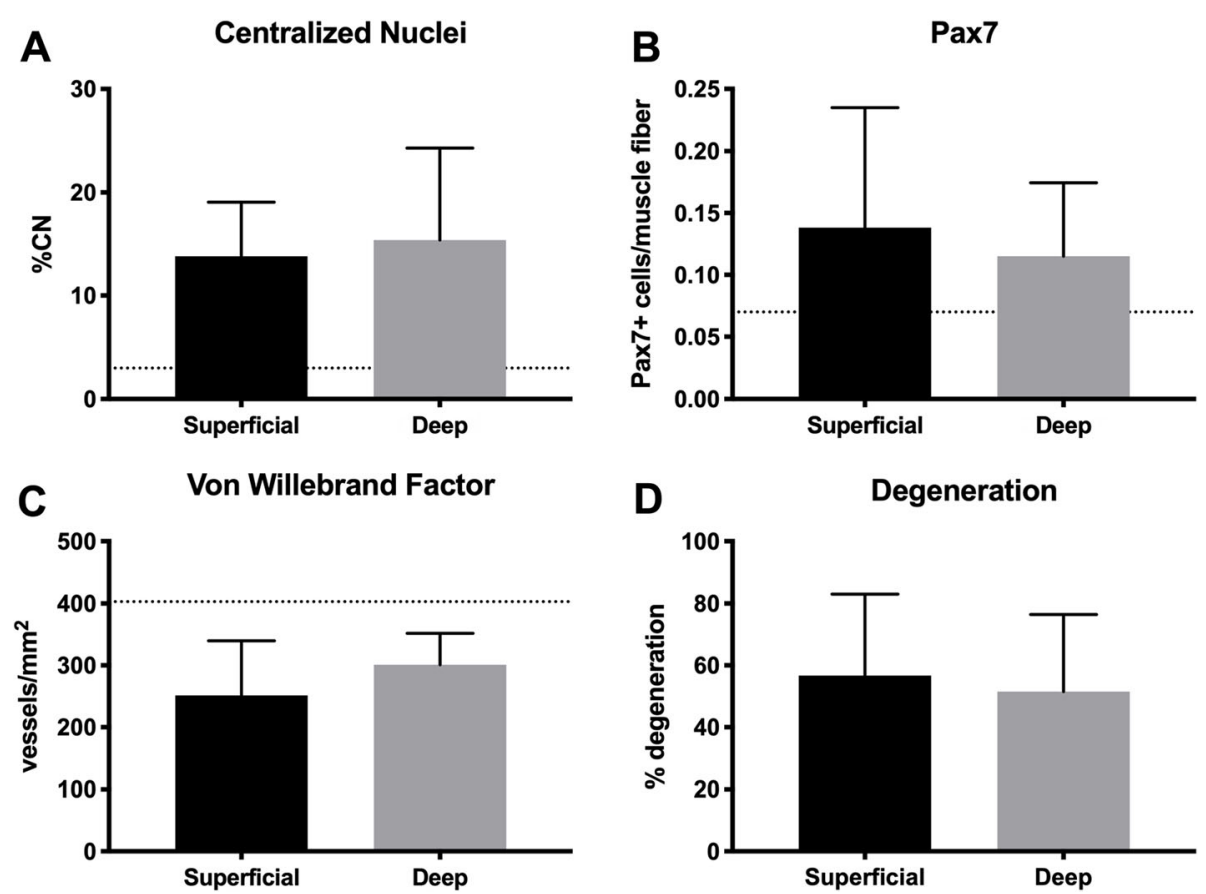

Fig. 5 Histologic measurements of muscle regeneration, vascularization, and degeneration. Muscle regeneration was defined by the percentage of fibers with centralized nuclei (a) and Pax $7^{+}$cells per muscle fiber (b), demonstrating elevation compared to prior literature in muscle [39, 40]. Vascularization was assessed by that number of Von Willebrand Factor positive vessels per square millimeter (c) demonstrating lower vascularity compared to prior literature in muscle [41]. Degeneration was quantified by the percentage of muscle fibers that exhibited signs of degeneration (moth eaten fibers, cell infiltration, core fibers, and myophagocytosis) per square millimeter. Measurements were made for both superficial (black) and deep (gray) biopsy samples

$0.21)$ or $\operatorname{Pax}^{+}$cells $(p=0.70, \mathrm{~d}=0.29)$, von Willebrand factor + vessels/area $(p=0.18,0.69)$, or histologic evidence of muscle degeneration $(p=0.35, \mathrm{~d}=0.20)$.

\section{MRI measured differences between superficial and deep} fat fraction of the multfidus muscle

Qualitatively, fatty infiltration of the posterior musculature was observed along the spinolaminar border, between the multifidus and erector spinae muscles, and in the posterior epimuscular fatty region of the erector spinae. As both the superficial and deep biopsy regions reside in regions of high fat content, it was not surprising that these areas quantitatively had high fat signal fractions. However, no significant difference in MRIassessed fat signal fraction was found between superficial and deep regions of interest coincident with where muscle biopsies were taken $(p=0.92, \mathrm{~d}=0.05$; Fig. 6).

\section{Discussion}

Contrary to our hypothesis, there were no significant differences between the superficial and deep regions of the multifidus for histologically measured area of fat, muscle area, fiber cross sectional area, muscle regeneration markers, muscle degeneration markers, and vascularization. While total collagen content between the two regions was the same, the superficial region of the multifidus was found to have less loose and more dense collagen than the deep region. These findings suggest that the functional differences that have been previously observed between the superficial

\section{MRI Fat Fraction}

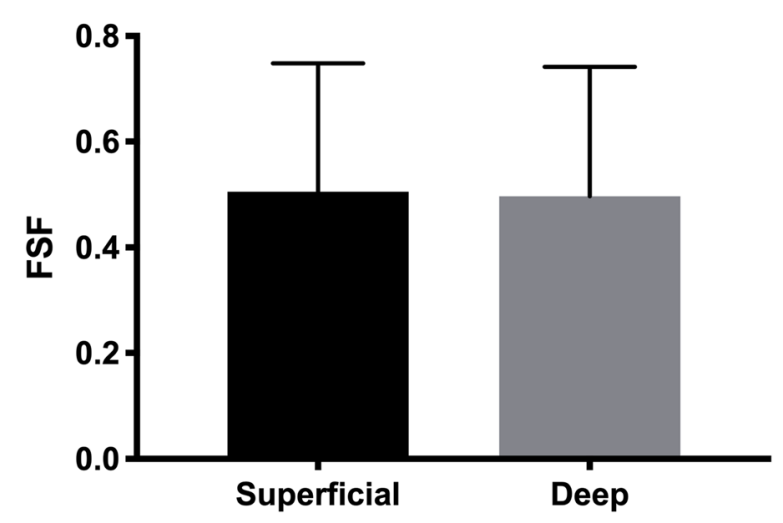

Fig. $6 \mathrm{MRI}$ measured fat signal fraction of the superficial (black) and deep (gray) regions of interest that corresponded to the approximate locations of where the multifidus was biopsied 
and deep regions of the multifidus are not a result of muscle composition, and that muscle degeneration does not occur preferentially in a given region of the multifidus.

Differences in paraspinal muscle activation during motion and muscle composition have been highlighted as targets in assessing both muscle health and potential for improvement with physical therapy $[22,42]$. Lumbar multifidus has been especially implicated given its assumed role in spinal stability and common pathological changes in LBP [43-47]. The role of the multifidus has further been parsed out based on its distinct superficial and deep layers, with the superficial multifidus thought to be involved primarily in lumbar extension and the deep multifidus focused on control of dynamic intersegmental stability via intervertebral compression, thus providing spinal stability $[22,25,48]$. Given these differences in activation patterns, it has previously been hypothesized that there would be differences in proportion of muscle fiber types between layers. Specifically, the deep multifidus would have a higher proportion of type 1 fibers compared to the superficial multifidus [22, 48], since type I fibers are fatigue resistant and most suitable to providing the constant low load activity necessary to provide dynamic lumbar stability. Importantly, this supposedly higher proportion of type I fibers in deep multifidus has been used as a target for the low load, tonic exercises often implemented in LBP exercise rehabilitation regimens $[22,49]$. Studies comparing the proportion of these fibers in patients have demonstrated conflicting results. One study examining both autopsy specimens and biopsies from patients undergoing surgery for disc herniation found a significantly greater proportion of type I fibers in deep multifidus [50]. However, the majority of the literature has demonstrated no difference in fiber-type distribution based on multifidus depth across a range of ages, consistent with the results in this study $[8,9,51-55]$.

Regional differences in collagen within the lumbar multifidus have not been thoroughly explored. Our histological results found that although the superfical and deep muscle biopsies both had an elevated area fraction of collagen $(\sim 25 \%)$ and superficial mutifidus biopsies had less dense collagen and more loose collagen than deep multifidus biopsies. Increased collagen expression within muscle tissue has been associated with chronic inflammatory changes and subsequent irregular remodeling thought to be related to LSP [56]. Such changes often accompany muscle atrophy and increased fat deposition to comprise what is defined as tissue fibrosis. Progression of paraspinal muscle fibrosis is associated with decline in muscle functionality and recovery at these late stages is prolonged. Previous animal studies examining thoracolumbar fascia (TLF) in rats have shown an organized distribution of collagen based on tissue depth, with more superficial layers having a higher percentage of densely packed collagen fibers compared to deeper layers of the TLF, which were composed of loose, irregularly oriented collagen fibers [57]. Increases in connective tissue within multifidus appear to be related to duration of LBP, with injury models only demonstrating increases in collagen area after several months [14]. Additionally, fibrotic gene expression has been shown to be upregulated in individuals with chronic symptoms compared to those with acute symptoms [58]. These results suggest that fibrotic deposition within muscle may affect muscle function in patients with LSP, further predisposing patients to maladaptive muscle changes and fatty infiltration. The mechanisms underlying the increase in collagen deposition in multifidus are not fully understood at this time, but physical activity appears to reduce the inflammation associated with this tissue fibrosis, which may improve whole muscle function [56, 59-64].

Markers of muscle vascularity, damage, and degeneration did not significantly differ between superficial and deep samples Although the average percentage of centralized nuclei for each biopsy level was higher than expected for healthy skeletal muscle (3\%), this percentage was lower than values reported for other studies examining lumbar spine pathology $[10,11]$. Despite the high proportion of markers for muscle recovery (centralized nuclei for regeneration and Pax7+ for satellite cell density), the number of muscle fibers that exhibited degenerative characteristics remained high. This is consistent with previous results from our group that suggest the amount of muscle degeneration in chronic LBP patients outpaces the ability to restore a healthy muscle phenotype $[10,65]$.

Although this study provides the first documented comparison between superficial versus deep histology and MR imaging of the lumbar multifidus in patients with LSP, there were several limitations that must be considered in assessing our results. First, the nature of biopsy collection was such that identifying and matching the exact corresponding region to the MRI was not possible. We defined an ROI on MRI as close to the biopsy location as possible, based on a standardized biopsy region in our protocol and biopsy level identification via intraoperative fluoroscopy. By involving a limited number orthopedic surgeons and training them on biopsy technique and location, we attempted to mitigate variability in biopsy location. Second, it is impossible to measure collagen from routine clinical imaging (i.e. T1weighted, T2-weighted MRIs) due to the short transverse relaxation time of fibrotic tissues. While MRI pulse sequenceses sensitive to collagen in tissues exist - such as ultrashort echo time - they are not routinely used to assess patients with LSP. Third, this was a prospective study and only 16 patients were included. However from this sample population, it was unlikely that differences in muscle microstructure/macrostructure between the 
superficial and deep multifidus would be evident with a larger sample size. Fourth, the majority of patients in this study all had an identifiable lumbar spine pathology such as stenosis or disc degeneration resulting in radicular symptoms, which may differentially impact superficial and deep regions of the multifidus as compared to nonspecific LBP. While biopsies from subjects with nonspecific LBP would allow for the differentiation of histological changes as a result of potential denervation, this patient population is less likely to receive surgical intervention without an identified anatomical pain generator and ethical issues often preclude obtaining regional biopsies. Furthermore, this study did not take into account some patient factors that have been implicated in muscle quality, such as spinal alignment $[66,67]$, or level of physical activity $[56,59]$.

\section{Conclusions}

The results of our study did not support the hypothesis that the deep region of the multifidus is more degenerated in patients with lumbar spine pathology, as gross degenerative changes in muscle microstructure and macrostructure were the same in the superficial and deep regions of the multifidus. Although total collagen deposition was similar between regions, we found that superficial biopsies of the muscle demonstrated a greater percent dense collagen and lower percent loose collagen compared to deep biopsies. However, the functional implications of differences in the distribution of loose and dense collagen are unclear. More studies are warranted to further elucidate functional contribution of loose and dense collagen deposition on multifidus passive mechanics in patients with degenerative lumbar spine conditions.

\section{Abbreviations}

DAPI: 4'6-diamidino-2-phenylindole; H\&E: Haematoxlyn \& eosin; LBP: Low back pain; LSP: Lumbar spine pathology; MRI: Magnetic resonance imaging; ROI: Region of interest; TLF: Thoracolumbar fascia

\section{Authors' contributions}

J.P. and D.B.B. contrbuted equally to this manuscript. Research design J.P. D.B.B., S.R.W., B.S. Data acquisition J.P., J.C.H., V.Z., R.T.A., S.R.G., B.S. Data analysis J.P., D.B.B., B.S. Manuscript preparation J.P., D.B.B., B.S. All authors have reviewed and approved the final submitted version of the manucript.

\section{Funding}

This study was funded by the National Institute of Health: R01HD088437.

\section{Availability of data and materials}

The datasets used and/or analyzed during the current study are available from the corresponding author on reasonable request.

\section{Ethics approval and consent to participate}

This experiment was conducted with approval from the UC San Diego InstitutionAl Review Board. All subjects provided oral and written consent to participate.

\section{Consent for publication}

Not applicable.

\section{Competing interests}

The authors declare that they have no competing interests.

\section{Author details}

'Departments of Medicine, University of California, San Diego, USA. ${ }^{2}$ Departments of Nanoengineering, University of California, San Diego, USA. ${ }^{3}$ Departments of Orthopaedic Surgery, University of California, 9500 Gilman Drive (MC0863), La Jolla, San Diego, CA 92093, USA. ${ }^{4}$ Departments of Radiology, University of California, San Diego, USA. ${ }^{5}$ Departments of Bioengineering, University of California, San Diego, USA.

Received: 18 July 2020 Accepted: 12 November 2020

Published online: 20 November 2020

\section{References}

1. Shahidi B, Parra CL, Berry DB, Hubbard JC, Gombatto S, Zlomislic V, et al. Contribution of Lumbar Spine Pathology and Age to Paraspinal Muscle Size and Fatty Infiltration. Spine (Phila Pa 1976). 2017;42:616-23.

2. Ivanova Jl, Birnbaum HG, Schiller M, Kantor E, Johnstone BM, Swindle RW. Real-world practice patterns, health-care utilization, and costs in patients with low back pain: the long road to guideline-concordant care. Spine J. 2011;11:622-32.

3. Carey TS, Garrett JM, Jackman A, Hadler N. Recurrence and care seeking after acute back pain: results of a long-term follow-up study. Med Care. 1999;37:157-64

4. Weinstein JN, Tosteson TD, Lurie JD, Tosteson ANA, Hanscom B, Skinner JS, et al. Surgical vs nonoperative treatment for lumbar disk herniation. The spine patient outcomes research trial (SPORT): a randomized trial. J Am Med Assoc. 2006;296:2441-50.

5. Hildebrandt M, Fankhauser G, Meichtry A, Luomajoki H. Correlation between lumbar dysfunction and fat infiltration in lumbar multifidus muscles in patients with low back pain. BMC Musculoskelet Disord. 2017;18:12.

6. Ward SR, Kim CW, Eng CM, Gottschalk L IV, Tomiya A, Garfin SR, et al. Architectural analysis and intraoperative measurements demonstrate the unique design of the multifidus muscle for lumbar spine stability. J Bone Jt Surg Ser A. 2009;91:176-85.

7. Hides J, Gilmore C, Stanton W, Bohlscheid E. Multifidus size and symmetry among chronic LBP and healthy asymptomatic subjects. Man Ther. 2008;13: 43-9.

8. Mannion AF, Weber BR, Dvorak J, Grob D, Muntener M. Fibre type characteristics of the lumbar paraspinal muscles in normal healthy subjects and in patients with low back pain. J Orthop Res. 1997;15:881-7.

9. Ng JK-F, Richardson CA, Kippers V, Parnianpour M. Relationship between muscle fiber composition and functional capacity of back muscles in healthy subjects and patients with back pain. J Orthop Sports Phys Ther. 1998;27:389-402.

10. Shahidi B, Hubbard JC, Gibbons MC, Ruoss S, Zlomislic V, Allen RT, et al. Lumbar multifidus muscle degenerates in individuals with chronic degenerative lumbar spine pathology. J Orthop Res. 2017;35:2700-6.

11. Zhao WP, Kawaguchi Y, Matsui H, Kanamori M, Kimura T. Histochemistry and morphology of the multifidus muscle in lumbar disc herniation: Comparative study between diseased and normal sides. Spine (Phila Pa 1976). 2000;25:2191-9.

12. Battié $M C$, Niemelainen $R$, Gibbons $L E$, Dhillon $S$. I l level- and side-specific multifidus asymmetry a marker for lumbar disc pathology? Spine J. 2012;12:932-9.

13. Kjaer P, Bendix T, Sorensen JS, Korsholm L, Leboeuf-Yde C. Are MRI-defined fat infiltrations in the multifidus muscles associated with low back pain? BMC Med. 2007;5:2.

14. Hodges PW, James G, Blomster L, Hall L, Schmid A, Shu C, et al. Multifidus Muscle Changes after Back Injury Are Characterized by Structural Remodeling of Muscle, Adipose and Connective Tissue, but Not Muscle Atrophy: Molecular and Morphological Evidence. Spine (Phila Pa 1976). 2015:40:1057-71.

15. Mooney V, Gulick J, Perlman M, Levy D, Pozos R, Leggett S, et al. Relationships between myoelectric activity, strength, and MRI of lumbar extensor muscles in back pain patients and normal subjects. J Spinal Disord. 1997;10:348-56

16. Willemink MJ, Van Es HW, Helmhout PH, Diederik AL, Kelder JC, Van Heesewijk JPM. The effects of dynamic isolated lumbar extensor training on lumbar multifidus functional cross-sectional area and functional status of 
patients with chronic nonspecific low back pain. Spine (Phila Pa 1976). 2012; 37:E1651-8.

17. Danneels LA, Vanderstraeten GG, Cambier DC, Witvrouw EE, Bourgois J, Dankaerts W, et al. Effects of three different training modalities on the cross sectional area of the lumbar multifidus muscle in patients with chronic low back pain. Br J Sports Med. 2001;35:186-91.

18. Berry DB, Padwal J, Johnson S, Englund EK, Ward SR, Shahidi B. The effect of high-intensity resistance exercise on lumbar musculature in patients with low back pain: a preliminary study. BMC Musculoskelet Disord. 2019;20:290.

19. LEWIN T, MOFFETT B, VIDIK A. The morphology of the lumbar synovial interveertebral joints. Acta Morphol Neerl Scand. 1962;4:299-319.

20. Macintosh JE, Valencia F, Bogduk N, Munro RR. The morphology of the human lumbar multifidus. Clin Biomech. 1986;1:196-204.

21. Jemmett RS, MacDonald DA, Agur AMR. Anatomical relationships between selected segmental muscles of the lumbar spine in the context of multi-planar segmental motion: a preliminary investigation. Man Ther. 2004;9:203-10.

22. MacDonald DA, Lorimer Moseley G, Hodges PW. The lumbar multifidus: does the evidence support clinical beliefs? Man Ther. 2006;11:254-63.

23. Macintosh JE, Bogduk N. The biomechanics of the lumbar multifidus. Clin Biomech. 1986;1:205-13.

24. Panjabi M, Abumi K, Duranceau J, Oxland T. Spinal stability and intersegmental muscle forces: A biomechanical model. Spine (Phila Pa 1976). 1989;14:194-200.

25. Moseley GL, Hodges PW, Gandevia SC. Deep and superficial fibers of the lumbar multifidus muscle are differentially active during voluntary arm movements. Spine (Phila Pa 1976). 2002;27:E29-36.

26. O'Sullivan PB, Twomey LT, Allison GT. Evaluation of specific stabilizing exercise in the treatment of chronic low back pain with radiologic diagnosis of spondylolysis of spondylolisthesis. Spine (Phila Pa 1976). 1997;22:2959-67.

27. McGill SM. Kinetic potential of the lumbar trunk musculature about three orthogonal orthopaedic axes in extreme postures. Spine (Phila Pa 1976). 1991;16:809-15.

28. Tuel SM. Mechanical low Back pain perspectives in functional anatomy. Am J Phys Med Rehabil. 1991;70:159.

29. Zoidl G, Grifka J, Boluki D, Willburger RE, Zoidl C, Krämer J, et al. Molecular evidence for local denervation of paraspinal muscles in failed-back surgery/ postdiscotomy syndrome. Clin Neuropathol. 2003;22:71-7.

30. Beneck GJ, Kulig K. Multifidus atrophy is localized and bilateral in active persons with chronic unilateral low back pain. Arch Phys Med Rehabil. 2012;93:300-6.

31. Saragiotto BT, Maher CG, Yamato TP, Costa LOP, Menezes Costa LC, Ostelo RWJG, et al. Motor control exercise for chronic non-specific low-back pain. Cochrane Database Syst Rev. 2016;2016:1284-95.

32. Ward SR, Takahashi M, Winters TM, Kwan A, Lieber RL. A novel muscle biopsy clamp yields accurate in vivo sarcomere length values. J Biomech. 2009;42:193-6.

33. Miller JL, Watkin $\mathrm{KL}$, Chen MF. Muscle, adipose, and connective tissue variations in intrinsic musculature of the adult human tongue. J Speech Lang Hear Res. 2002:45:51-65.

34. Abràmoff MD, Magalhães PJ, Ram SJ. Image processing with imageJ. Biophoton Int. 2004;11:36-41.

35. Qu Z, Andersen JL, Zhou S. Visualisation of capillaries in human skeletal muscle. Histochem Cell Biol. 1997;107:169-74.

36. Bourne AJ. Muscle biopsy: a practical approach. Pathology. 1986;18:359.

37. Berry DB, Padwal J, Johnson S, Parra CL, Ward SR, Shahidi B. Methodological considerations in region of interest definitions for paraspinal muscles in axial MRls of the lumbar spine. BMC Musculoskelet Disord. 2018;19:135.

38. Cohen J. Statistical Power Analysis for the Behavioral Sciences. 2nd ed. New York: Lawrence Erlbaum Associates; 2013.

39. Sorarù G, D'Ascenzo C, Polo A, Palmieri A, Baggio L, Vergani L, et al. Spinal and bulbar muscular atrophy: skeletal muscle pathology in male patients and heterozygous females. J Neurol Sci. 2008;264:100-5.

40. Macaluso F, Brooks NE, Vyver M, Tubbergh K, Niesler CU, Myburgh KH. Satellite cell count, VO2max, and p38 MAPK in inactive to moderately active young men. Scand J Med Sci Sports. 2012;22:e38-44

41. JØrgensen K, Nicholaisen T, Kato M. Muscle fiber distribution, capillary density, and enzymatic activities in the lumbar paravertebral muscles of young men: Significance for isometric endurance. Spine (Phila Pa 1976). 1993;18:1439-50.

42. Lamoth CJC, Meijer OG, Daffertshofer A, Wuisman PIJM, Beek PJ. Effects of chronic low back pain on trunk coordination and back muscle activity during walking: changes in motor control. Eur Spine J. 2006;15:23-40.

43. Panjabi MM. The stabilizing system of the spine: part I. function, dysfunction, adaptation, and enhancement. J Spinal Disord. 1992;5:383-9.
44. Wilke HJ, Wolf S, Claes LE, Wiesend A, Arand M. Stability increase of the lumbar spine with different muscle groups-a biomechanical in vitro study. Spine (Phila Pa 1976). 1995;20:192-8.

45. Goel VK, Kong W, Han JS, Weinstein JN, Gilbertson LG. A combined finite element and optimization investigation of lumbar spine mechanics with and without muscles. Spine (Phila Pa 1976). 1993;18:1531-41.

46. Danneels L, Coorevits P, Cools A, Vanderstraeten G, Cambier D, Witvrouw E, et al. Differences in electromyographic activity in the multifidus muscle and the iliocostalis lumborum between healthy subjects and patients with subacute and chronic low back pain. Eur Spine J. 2002;11:13-9.

47. Rantanen J, Hurme M, Falck B, Alaranta H, Nykvist F, Lehto M, et al. The Lumbar Multifidus Muscle Five Years After Surgery for a Lumbar Intervertebral Disc Herniation. Spine (Phila Pa 1976). 1993;18:568-74.

48. Dickx N, Cagnie B, Achten E, Vandemaele P, Parlevliet T, Danneels L. Differentiation between deep and superficial fibers of the lumbar multifidus by magnetic resonance imaging. Eur Spine J. 2010;19:122-8.

49. Arokoski JP, Valta T, Airaksinen O, Kankaanpää M. Back and abdominal muscle function during stabilization exercises. Arch Phys Med Rehabil. 2001;82:1089-98.

50. Sirca A, Kostevc $V$. The fibre type composition of thoracic and lumbar paravertebral muscles in man. J Anat. 1985;141:131-7.

51. Bagnall KM, Ford DM, McFadden KD, Greenhill BJ, Raso VJ. The histochemical composition of human vertebral muscle. Spine (Phila Pa 1976). 1984;9:470-3.

52. Ford D, Bagnall KM, McFadden KD, Greenhill B, Raso J. Analysis of vertebral muscle obtained during surgery for correction of a lumbar disc disorder. Cells Tissues Organs. 1983;116:152-7.

53. Regev GJ, Kim CW, Thacker BE, Tomiya A, Garfin SR, Ward SR, et al. Regional Myosin Heavy Chain Distribution in Selected Paraspinal Muscles. Spine (Phila Pa 1976). 2010;35:1265-70.

54. Mannion AF, Käser L, Weber E, Rhyner A, Dvorak J, Müntener M. Influence of age and duration of symptoms on fibre type distribution and size of the back muscles in chronic low back pain patients. Eur Spine J. 2000;9:273-81.

55. Rantanen J, Rissanen A, Kalimo H. Lumbar muscle fiber size and type distribution in normal subjects. Eur Spine J. 1994:3:331-5.

56. James G, Klyne DM, Millecamps M, Stone LS, Hodges PW. ISSLS prize in basic science 2019: physical activity attenuates fibrotic alterations to the multifidus muscle associated with intervertebral disc degeneration. Eur Spine J. 2019:28:893-904.

57. Tesarz J, Hoheisel U, Wiedenhöfer B, Mense S. Sensory innervation of the thoracolumbar fascia in rats and humans. Neuroscience. 2011;194:302-8.

58. Shahidi B, Fisch KM, Gibbons MC, Ward SR. Increased Fibrogenic Gene Expression in Multifidus Muscles of Patients with Chronic Versus Acute Lumbar Spine Pathology. Spine (Phila Pa 1976). 2019;1:E973-974.

59. James G, Millecamps M, Stone LS, Hodges PW. Dysregulation of the Inflammatory Mediators in the Multifidus Muscle After Spontaneous Intervertebral Disc Degeneration SPARC-null Mice is Ameliorated by Physical Activity. Spine (Phila Pa 1976). 2018:43:E1184-94.

60. Petersen AMW, Pedersen BK. The anti-inflammatory effect of exercise. J Appl Physiol. 2005:98:1154-62.

61. Pedersen BK. Anti-inflammatory effects of exercise: role in diabetes and cardiovascular disease. Eur J Clin Investig. 2017:47:600-11.

62. Gleeson M, Bishop NC, Stensel DJ, Lindley MR, Mastana SS, Nimmo MA. The anti-inflammatory effects of exercise: mechanisms and implications for the prevention and treatment of disease. Nat Rev Immunol. 2011;11:607-15.

63. Brandt C, Pedersen BK The role of exercise-induced Myokines in muscle homeostasis and the defense against chronic diseases. J Biomed Biotechnol. 2010;2010:1-6.

64. Pedersen BK, Feigh M, Pedersen BK. Persistent low-grade inflammation and regular exercise. Front Biosci. 2010;\$2:48.

65. Shahidi B, Gibbons MC, Esparza M, Zlomislic V, Allen RT, Garfin SR, et al. Cell populations and muscle fiber morphology associated with acute and chronic muscle degeneration in lumbar spine pathology. Jor Spine. 2020;3:E1087.

66. Meakin JR, Fulford J, Seymour R, Welsman JR, Knapp KM. The relationship between sagittal curvature and extensor muscle volume in the lumbar spine. J Anat. 2013;222:608-14.

67. Pezolato A, de Vasconcelos EE, Defino HLA, Nogueira-Barbosa MH. Fat infiltration in the lumbar multifidus and erector spinae muscles in subjects with sway-back posture. Eur Spine J. 2012;21:2158-64.

\section{Publisher's Note}

Springer Nature remains neutral with regard to jurisdictional claims in published maps and institutional affiliations. 